\title{
Chris Baber
}

University of Birmingham, Great Britain

\section{THINKING THROUGH TOOLS: WHAT CAN TOOL-USE TELL US ABOUT DISTRIBUTED COGNITION?}

\begin{abstract}
In this paper, I question the notion that tool-use must be driven by an internal representation which specifies the "motor program" enacted in the behaviour of the tool-user. Rather, it makes more sense to define tool-use in terms of characteristics of the dynamics of this behaviour. As the behaviour needs to be adjusted to suit changes in context, so there is unlikely to be a oneto-one, linear mapping between an action and its effect. Thus, tool-use can best be described using concepts from Nonlinear Dynamics. Such an approach can be used to create a sort of cybernetic model of tool-use. However, there is a danger that such a model can either lead us back to internal representations (in that the comparator used to evaluate feedback during behaviour could be assumed to be pre-defined) or could fail to capture cognitive aspects of behaviour. In particular, the question of how the craftworker's intent can be enacted in the use of tools to produce a specific object seems to be lost in the cybernetic account. My solution is two-fold. First, the "model" is created on-the-fly and adapted through moment-by-moment interactions in the system of tool-user-tool-material-environment. This means that, rather than assuming a pre-defined internal representation that drives behaviour, I propose that cognition involves the selection of salient parameters that characterize the behaviour and the continued monitoring and management of behaviour in terms of these parameters. Second, intent is only loosely defined a priori but crystallizes through the continued interactions between craftworker and object through a process in which the affordances of the object become apparent to, and responded to by, the craftworker.
\end{abstract}

Keywords: affordance, tool-use, internal representation, nonlinear dynamics

\section{Craftwork and Tool-Use}

For the craft worker, a tool is the means by which intention is imposed on raw material; the tool disappears from immediate awareness in the smooth, skilful performance of the craft-worker's art. For me, this raises two fundamental questions relating to the use of tools and the relation between tool-use and cognition. The first concerns what we might mean by intention 


\section{Chris Baber}

in the actions of the tool-user. The second concerns what we might mean by immediate awareness and skilful performance. I suggest that the answer to both of these questions lies in the concept of affordance that Gibson (1979) proposed - but not in a form that relies on the mere properties of objects. One reading of Gibson's (1979) notion of affordance (and he offers several competing readings in his work) is to regard specific properties of an object as evoking specific capabilities of the actor (animal or human). In order for this pattern of response to succeed, so the argument runs, affordance arises partly from perception-action coupling and partly from intentionaction coupling; perception-action coupling allows a specific action to be encouraged in response to the perception of specific cues in the object (in a sort of bottom-up manner from stimulus to response; thus, a cup "affords" being picked up), and intention-action coupling allows a specific action to be encouraged in support of a specific goal of the actor (in a sort of topdown manner from goal to action; thus, picking up a cup to drink from involves a different set of actions to picking up the same cup to put into a cupboard). As we put it in a previous paper, "perception-action coupling is mediated by the intentionality of the actor" (Baber et al., 2014). Indeed, Rosenbaum (1980) shows how the actions performed are often related less to the physical appearance of the object and more to the end-state of the action that the user is performing. He uses the example of turning an inverted wineglass so that it can have wine poured into it; the hand approaches the glass in an uncomfortable, twisted posture because the final state of the hand, when the glass is upright, will be normal. Van Leeuwen et al. (1994) have argued that there is a hierarchy of affordances, in which actions are embedded in this flow of bottom-up and top-down processing. It is this hierarchy of affordances which gives special prominence to tool-use. Rather than tool-use being simply a form of manipulating physical objects, one could regard the intentionality in tool-use as creating a further level of cognitive demand on the tool-user, i.e., picking up a screwdriver to move from one place to another is substantively different from picking up the screwdriver and driving a screw into a piece of wood. This difference is not solely due to the nature of the physical actions performed but also due to the evaluation of the outcome of the action and the specificity of the target state. It is these notions of evaluation and target state that define intention for the tool-user.

Talk of outcomes, target states, intention etc., implies that the use of tools is driven by a set of cognitive processes. One could assume that all aspects of tool-use can be reduced to well-coordinated physical activity, and this might suggest that there is little or no place for cognition in the use of tools. On the other hand, one might consider the type of physical ac- 
tivity involving tools to require a well-specified plan that not only reflects the tool-user's intention but also the sequence of actions that are necessary to bring this intention to life. From this perspective, tool-use could be seen as a means of running a well-written program of motor commands. Having set up two extremes (one involving no apparent need for cognition, the other involving action subservient to cognitive processes), I want to explore something of a middle ground. In broad terms, I believe that it makes sense to assume that there is cognitive activity which coordinates skilled motor control but that it need not make sense to assume that this cognitive activity takes the form of pre-defined programs. Rather I assume that motor control arises from the interactions between the tool-user and the tools and materials being used, and that a defining aspect of skill in this respect lies in the management of parameters which characterise these interactions. In a sense, my view of tool-use owes more to cybernetics than to psychology (although, rather than assuming the control is entirely based on feedback, I assume that there is some form of "feed-forward" but that this is not necessarily reliant on stored representations).

In support of this proposal, I draw on the notion of radical embodied cognitive science (Chemero, 2009) in which cognition arises from the physical interactions between actors and their environments rather than from mental representations of these environments. One consequence of this approach is that it is essential to consider the "system" of tool-user-toolmaterial-environment, and the manner in which this system operates rather than to assume that the tool-user imposes his/her will on the material through a tool. This follows from Gibson's (1979) notion of complementarity, and allows the definition of affordance to relate to the state of the system. For this paper, affordance, therefore, comes from the interactions in the tool-user-tool-material-environment system and can be considered, following concepts from Dynamical Systems, as an attractor state in the system. This results in two propositions. First, differences in skill level for toolusers can be explained in terms of the manner in which attractor states are managed. Second, much of the "representation" when using tools can either be external, i.e., in terms of the physicality of the tools themselves and the materials being worked, or in the form of coordinative structures, i.e., Bernstein's (1967) notion of well-practised musculoskeletal grouping that are recruited for the performance of a specific task. In a previous paper, this argument was used to explain why it is possible to argue that the wealth of evidence from neuropsychological imaging, e.g., of brain activity during tool recognition and manipulation tasks, need not indicate a causal link from brain activity to tool-use so much as the activation of regions of the 


\section{Chris Baber}

brain when tools are used; in other words, brain activation need not drive tool-use but, rather occurs, as a result of the interactions in the tool-usertool-material-environment system (Baber, 2003, 2006; Baber et al., 2014). In this paper, I review some of the evidence that my research team has been collecting in the study of tool-use. For this paper, I will focus on activities associated with jewellery making.
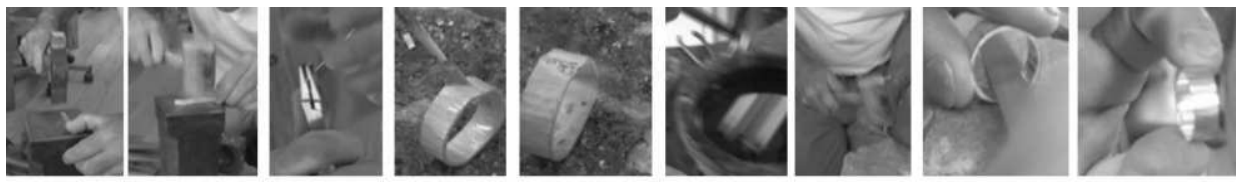

Figure 1. Stages in making a ring

Figure 1 presents a sequence of images that characterise the process of making a ring from metal. In summary, a strip of metal is sawn from a longer piece of metal; the strip is measured to be slightly larger than a particular size. The strip is placed on a mould with a design which is hammered into the metal. Then the strip is hammered flat before being bent into a circle using round-edge jewellery pliers. Notice how the first two frames employ different hammers, each with its own purpose and each with its own design. Having formed a ring, flux and solder are painted onto the joint and this is heated with a blow-torch. The heated ring is plunged into water to quench the heat and then hammered onto a form which defines the ring size. The ring is finished by filing until the desired effect is produced.

\section{Representing and Sketching Intent}

My team and I have spent many occasions observing and speaking to student and professional jewellers and often ask how they know what to make. More often than not, the question is greeted with confusion because it implies a level of "knowing" that the jewellers find difficult to articulate. This difficulty might relate to the problems of putting physical actions into words but I believe also stems from the fact that the "intention" of the jeweller is only loosely specified. For example, Figure 2 shows a sketch that a jeweller used to explain his "plan" for making a ring with a mount for a stone. The sketch describes the material that he will use ("shank wire $2 \frac{1}{4}$ inches long by $4 \times 4 \mathrm{~mm}$; flat metal for collets 40 thou; 18 ct white 1 inch $\times 6 \mathrm{~mm}$ and 18 ct yellow 40 thou $\left.\times 1 \frac{1}{2} \times 6 \mathrm{~mm}^{1}\right)$. The "design" that he was making is shown in three places on the sheet: in the top right, there is a sketch 
Thinking Through Tools: What Can Tool-Use Tell Us...

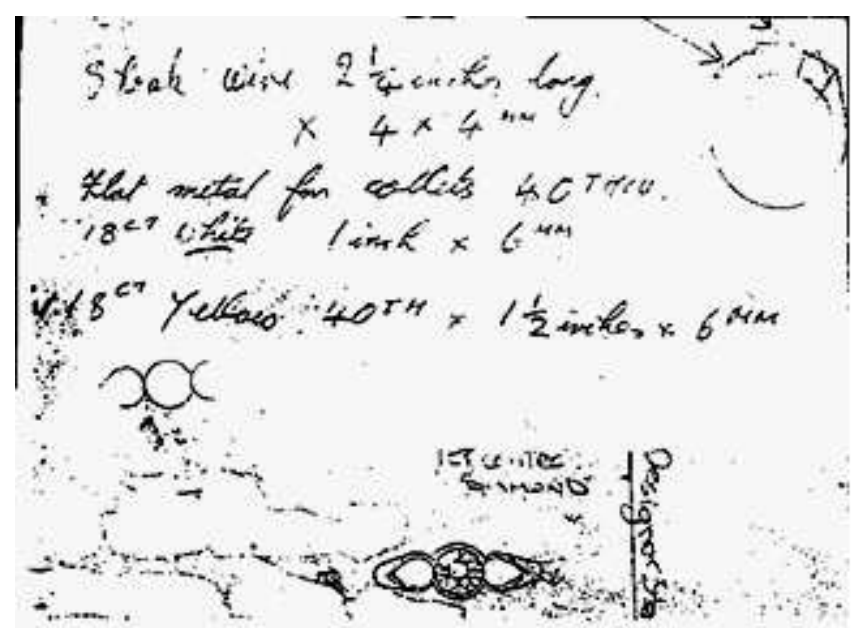

Figure 2. A jeweller's sketch

of the bevelling of the setting, just below the writing there are three circles to signify relative dimensions of stone and setting and at the bottom of the page is an outline of the stone in its setting. The point is that this is not a plan or a specification to be followed so much as an indication of intent; this is the sort of thing that he will be doing and, while the actual result might look similar, it is not being prescribed by this plan. Rather, the "plan" developed in response to the production of the ring. During the production, the ring was continually checked (by eye) and minor adjustments made (Figure 3).

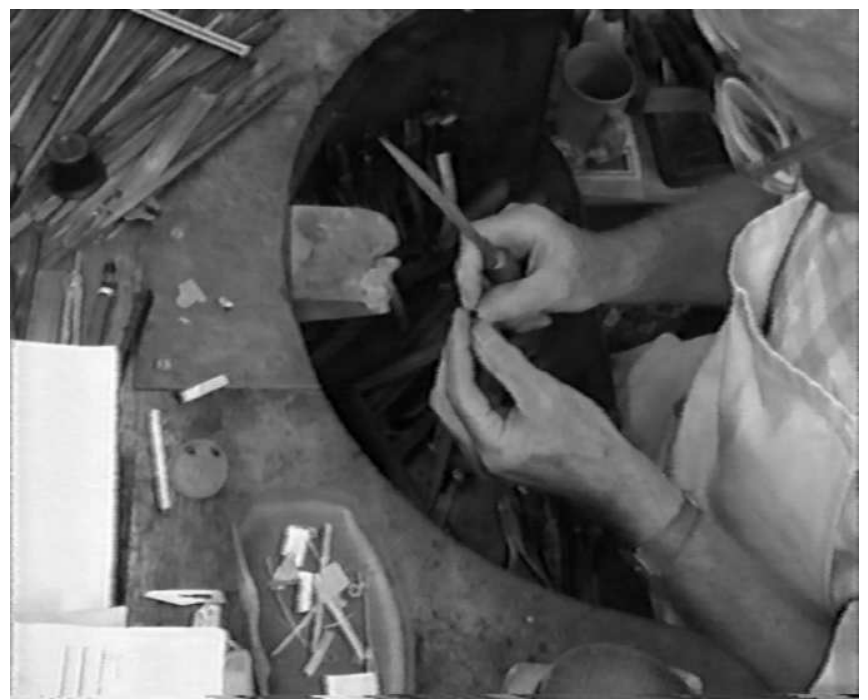

Figure 3. A jewellery maker filing a gold ring 


\section{3. "Workmanship of Risk", "Workmanship of Certainty"}

David Pye (1988) distinguished "certainty" and "risk" in his discussion of craft-work and manufacture. In the "workmanship of certainty", manufacture is repeatable and consistent; standardized parts are fitted to pre-made jigs and fixtures to ensure that all versions of an object are exactly the same. In this case, uncertainty or inconsistency is designed out of the process. For example, a small workshop producing chairs might need to make each chair leg to specific dimensions and seek to ensure that there is little or no variation in their design (so that the legs are interchangeable and can be fitted to any of the chairs being made).

In contrast, "workmanship of risk" has little or no clearly defined plan (beyond the overall intention to produce a particular type of product of particular dimensions). Rather, the craft-worker is continually adjusting action on the basis of the response of the material. Expert wood carvers speak of the sculpture "revealing" itself to them, and they attempt to exploit features of the wood, for example the line of the grain or the presence of knots, in ways that novices simply cannot. As Cutler (1994) points out in his review of Byzantine ivory carving, "Manifestations of the grain are irregular in elephant ivory. . . . When they occur, . . . they are obviously delighted in" (Cutler, 1994, p. 80). It would seem then, that craftwork is not so much a matter of tool-users performing a predetermined sequence of actions, as activity which arises from their interactions with the materials and the tools they use: ". . . performance can be rapidly adapted to the requirements of the task, tool or material" (Baber, 2003, p. 68). This question of flexibility raises the challenge of how to define motor control, particularly the trade-off between consistency and variability that we observe in skilled tool-use.

\section{4. "Behaviour is Regular Without Being Regulated"}

A defining aspect of human motor performance is its variability (Newell \& Corcos, 1993). On the one hand, the outcome of actions can be highly consistent, particularly for skilled performers. On the other hand, as Bernstein (1967) pointed out, motor control exhibits redundancy, with different forms of action relying on using different degrees of freedom. So, how are movement solutions selected from the very large space of possibilities defined by multiple degrees of freedom?

Figure 4 shows a jewellery student sawing a piece of copper. The copper is held against a "peg" and a piercing saw used to make the cut. We attached 


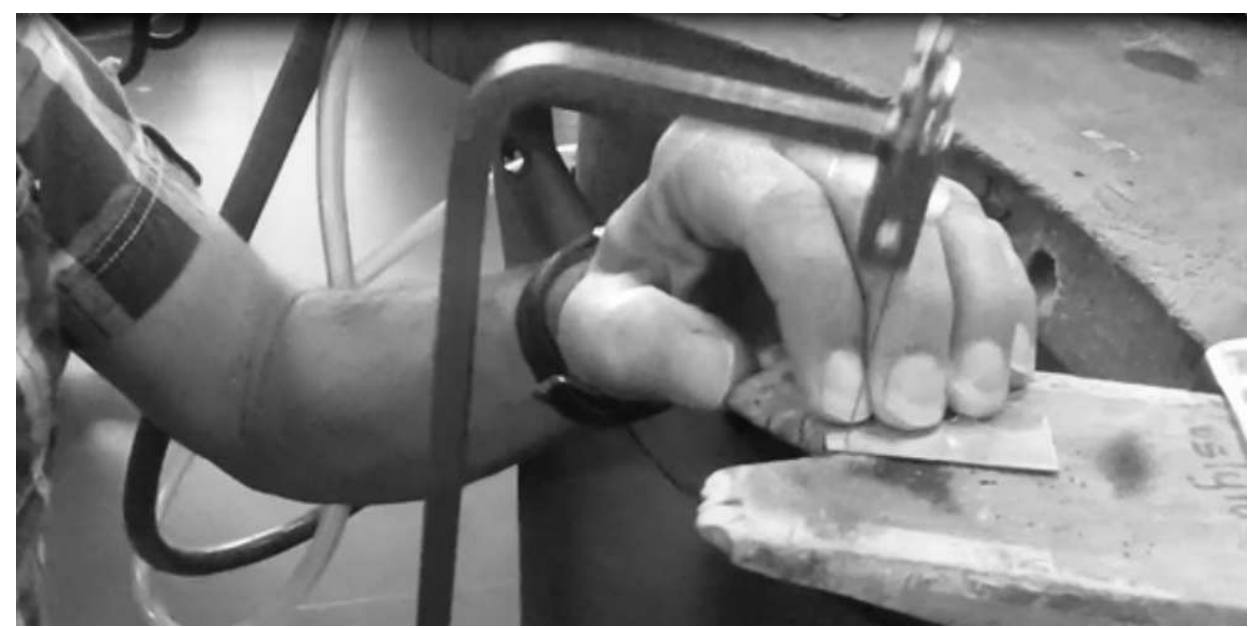

Figure 4. Sawing a piece of copper

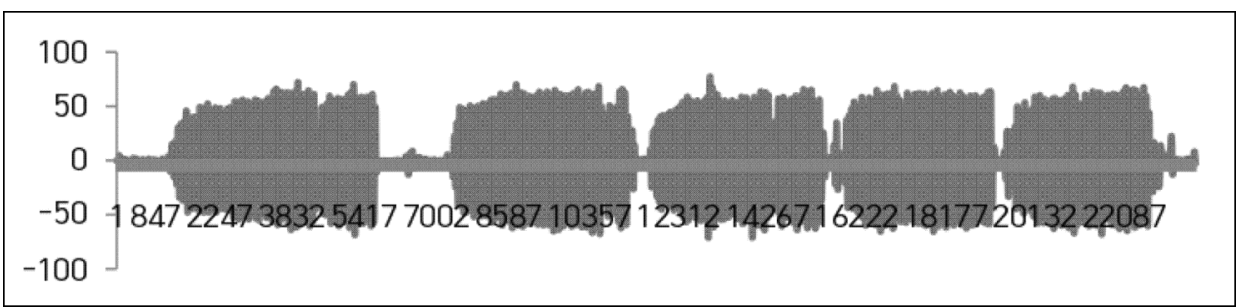

Figure 5. Velocity profile of cutting five separate lines in a piece of copper

accelerometers to the handle of this saw, which allows us to capture a velocity profile, as shown in Figure 5. This data collection is described in more detail in Baber et al. (2015a). Notice that the trace in Figure 5 seems to be divided into five blocks. Each block captures the movement of the saw in cutting a single line (of $1 \mathrm{~cm}$ in length) in the copper. Notice how these blocks are similar and yet distinctive. This illustrates the manner in which performance can be consistent but exhibit variability.

"Locomotion and manipulation . . . are controlled not by the brain but by information. . . . Control lies in the animal-environment system. . . . The rules that govern behavior are not like laws enforced by an authority or decisions made by a commander; behavior is regular without being regulated. The question is how this can be" (Gibson, 1979, p. 225). Thus, optimal control would seek to determine the "cost function" which is being minimized while allowing the goal of the movement to be achieved.

Turning to the jeweller cutting metal with a saw, one would expect movement to be regular and repetitive, with little variability (except when, 


\section{Chris Baber}

perhaps, the saw-teeth become snagged or clogged). One would expect such a task to be trivially easy and that there would be little difference between instances of the sawing task. We can see consistency between the five cuts in Figure 5. The apparent consistency between individuals could arise from a common internal representation of "how to use a saw", or from common mechanical constraints (e.g., an internal oscillator which operates at the same frequency), or from the constraints that the saw and sawing action places on the activity that a person can perform. For Gibson (1979) action arises from the human-environment system. Similarly, Newell and Corcos (1993) note that the constraints from the human-task-environment served to reduce the number of degrees of freedom available to the actor. I am interested in whether dexterity is a function of individual difference in motor control or whether it is a function of the tool-user-tool-materialenvironment system. In order to address tool-use from a systems perspective, it makes sense to see variability in terms of the ways in which motor control varies in order to match the demands imposed by the external environment. In this manner, variability becomes a consequence of system activity and we require a means of defining this variability in terms of system activity and control. Before exploring this, it is useful to review internal representation in motor control.

\section{Why Does Human Motor Control not Need Internal Representations?}

In order to address this question, we need to begin with a brief discussion as to why internal representations have been proposed to explain motor control. Imagine a common action, say hammering a nail into a wall in order to put up a picture. In this activity, the nail is positioned on the wall, the hammer grasped and then used to knock the nail into the wall. As long as the head of the hammer makes contact with the nail with sufficient force, the goal will be achieved (although too much force or hammering for too long could mean that the nail is entirely driven into the wall, leaving no part exposed on which to hang the picture). In order to perform this activity, it is important that the forces involved (in terms of swinging the hammer, striking the nail, driving the nail into the wall) are appropriately controlled, that the motion of the hammer is as efficient as possible and that extraneous and unwanted consequences (such as striking the finger or thumb holding the nail) are minimised. Given the degrees of freedom in the human arm, there is a need to manage the possible combinations to 
ensure smooth movement. Thus, the control of movement becomes a matter of managing the degrees of freedom and of managing the forces involved in this activity, together with managing the relationship between motion and goal state (i.e., the head of the nail rather than your thumb). In broad terms, there are three approaches to addressing this control problem.

The first is to assume that management of action involves a set of specifications which define which muscles are activated, by how much etc., e.g., in the form of an action schema (Norman \& Shallice, 1986; Schmidt, 2003) or generalised motor program (Summers \& Anson, 2009). This approach ties in with much of the recent neuroimaging work on tool-use, in which specific regions of the brain (notably left medial fusiform gyrus, left intraparietal sulcus, and left ventral premotor cortex) seem to be active when naming tools, observing tool-use, or planning movements with tools (Chao \& Martin, 2000; Grafton et al., 1997; Higuchi et al., 2007; JohnsonFrey, 2004; Krist, 2012; Martin, 2007). Indeed, Weisberg et al. (2007) suggest that these activations may reflect the retrieval of motor programs associated with tool-use.

A second approach is to assume that, rather than people having predefined programs or schema which are "run" when required, people seek the parameters which characterise a given activity and then manage these parameters in an optimal manner. For example, assume that all possible degrees of freedom can be brought together into a model of possible movements. This model could be described by sets of three-dimensional surfaces, or manifolds, within which actions can occur. In this approach, the goal of the actor is to select the most appropriate manifold and then manage the various parameters to ensure that they remained within the space defined by the manifold (Latash et al., 2002).

A third approach assumes that biological systems self-organise according to environmental, biomechanical, morphological constraints (Kamm et al., 1990; Kelso, 1995; Thelen, 1995). From this perspective, behaviour is defined in terms of variability around a fixed point, which is termed an attractor state. Potentially, the relationship between the input and output of the system appears to be random but can be shown to follow an underlying lawful, or predictably regular, pattern. Thus, non-linear dynamical systems can be thought of as a form of chaos and can be found in many aspects of human and organisational behaviour (Guastello, 2000). For example, when people perform simple, regular motions (such as tapping) their movements show a degree of variability. In other words, when one plots distance against velocity for the motions, rather than simply repeating the same pattern, the motions seem to fall in a space of overlapping curves. 


\section{Chris Baber}

The three approaches can be considered as being increasingly less reliant on the concept of a stored representation which drives behaviour, with the latter implying a synergy between the actions of the person and the constraints of the environment. While it is possible to postulate internal representations for different actions, such an approach runs into problems when attempting to explain variability (either in terms of changes in performance in different situations or in terms of differences in performance in novice and experts). A typical response to variability from the internal representation perspective is that this arises from "noise" in the system, and that such "noise" can either be ignored (because it is a random perturbation of the planned action) or can be dismissed (because it arises from an incomplete program that the novice is still acquiring). From a Systems Dynamics perspective, noise becomes an integral aspect of performance and, rather than something to dismiss or ignore, can be used to help characterise the manner in which actions are managed. In the next sections, I show examples of data collected in my laboratory that illustrate some of these points.

\section{Tool-Use as Consistent Performance}

The saw shown in Figure 4 was used by experienced (i.e., 3rd year) and inexperienced (i.e., 1st year) jewellery students. By plotting the velocity of motion (when sawing) in the $\mathrm{z}$ axis against distance in the $\mathrm{z}$ axis, it is possible to determine profiles which can distinguish "good", i.e., consistent and stable performance from "poor", i.e., erratic. This is illustrated by Figure 6 . One interpretation of these figures is that the "good" performer exhibits stable, consistent performance in which the movement of the sawing is bound by the constraints of the attractor state in which the action occurs, while the "poor" performer is unable to discover this attractor state.
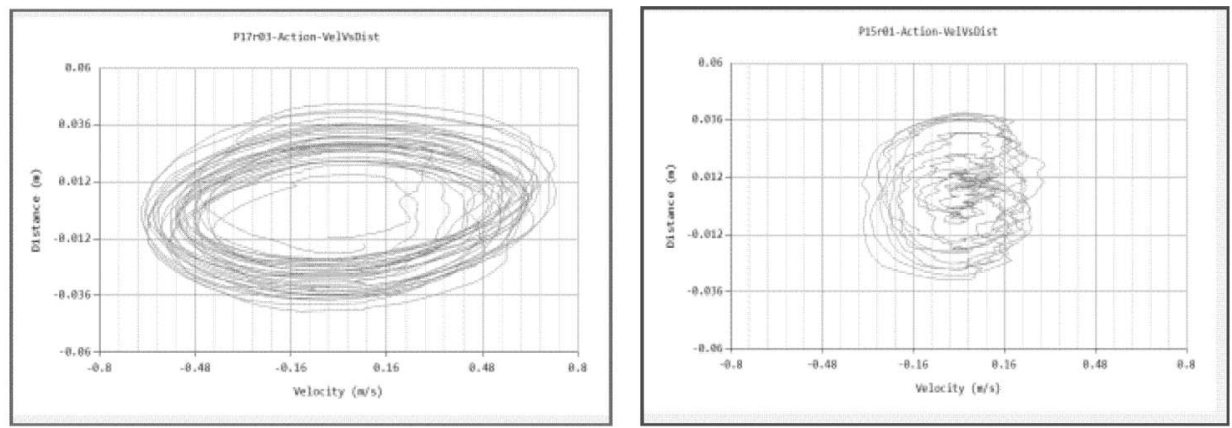

Figure 6. Velocity profile of participant 17 (3rd year, "good") and participant 15 (1st year, "poor") 


\section{Tool-Use as Controlled Performance}

In any dynamical system, variability in performance follows a $1 / f$ scaling (Kello et al., 2007; van Orden et al., 2003; Wagenmakers et al., 2004). Typically, this scaling is explained by the noise in the system which generates the signal: white noise arises from a random generator and is typified by data with no discernible trend, i.e., a line of best fit would be horizontal. On the other hand, pink noise has a power spectral density inversely proportional to frequency, implying some stability in the generator. This means that the line of best fit is a negative slope. Figure 7 shows data from 1st and 3rd year jewellery students sawing discs from pieces of copper. This shows the trace of a 1st year student, on the left, with that of a 3rd year student, on the right. The data collection and analysis for these figures are described in detail in Baber et al. (2015b). The slope on the right is far more pronounced than that on the left. From the assumptions of $1 / f$ scaling, this implies that the slope on the right is produced by a "system" with greater meta-stability than that on the left. The implication is that some of the students demonstrate greater stability in their sawing action than others, implying not only more consistent control but also greater mastery of variability in their actions.
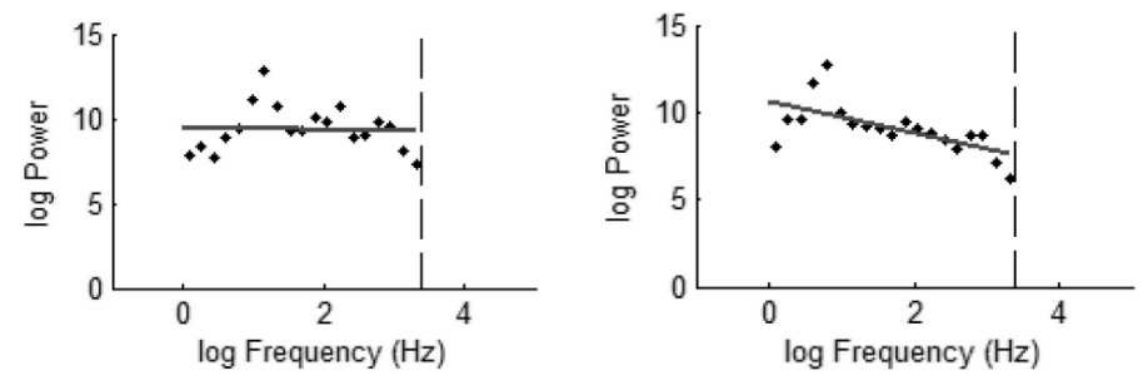

Figure 7. Plots of log power $\mathrm{x} \log$ frequency for sawing tasks

\section{Tool-Use as Parameter Optimisation}

Considering the kinematics of tool-use, as in the previous sections, could be taken to imply that this activity involves the use of feedback from the system in order to maintain a stable state of activity, i.e., an attractor state in system operation. As long as the attractor state has been found, the role of the tool-user would be to ensure that activity kept within the constraints set by this state. This cybernetic, optimal control model can be used to explain a wide range of motion control data. However, it leaves 


\section{Chris Baber}

open the question of whether there is a need for cognition in such activity. At his most extreme, Gibson (1979) felt that there was no need for cognition in the explanation of motor control. The explanation can be found entirely in the optimal control of a well-balanced system of person-objectenvironment. While this removes the need to think about representation, it begs the question of how might an actor know how to recognise and respond to the constraints set by the attractor state. In her work on flintknapping, Blandine Bril and her colleagues propose that performance can be defined by classes of parameters, e.g., control parameters defined by the properties of the tools, materials, environment, etc. and to which the person needs to adapt; regulatory parameters defined by characteristics of the actions being performed, such as trajectory of movement; functional parameters, not directly under the control of the person but which define the "goal" of the system, such as the kinetic energy required to remove a flake of stone of specific size. Studies suggest that the expert is better able, than the novice, to recognise and respond to these parameters (Biryukova \& Bril, 2012; Bril et al., 2010; Parry et al., 2014; Rein et al., 2013; Roux et al., 1995). We have applied these notions to the study of jewellery making and shown differences in control, regulatory, and functional parameters between "good" and "poor" performance, such that "good" performers tended to move the saw in a faster, more consistent manner, indicative of a smoother sawing action and tended to exert as little force as possible on the handle of the saw and, consequently, on the saw blade itself (Baber et al., 2015a). What was instructive was that the "good" performers might have described their goal as to "let the saw do the work" or as "using a light grip and all the saw-blade", which implies an awareness of the parameters that they need to control. The question is whether this statement of goal constitutes an internal representation to which they were working, or whether it is a description of the actions they perform after the fact.

\section{Discussion}

Tool-use constitutes a peculiar form of object-oriented action. The goal of the interaction is not to engage with the object per se but rather to manipulate the object in order to effect change in some other object or material. This means that, in addition, to wielding the tool, the tool-user needs to be cognizant of the changing states of the object or material being worked on, and to recognise when these changing states are satisfactory. This pa- 
per began by noting that tool-use involves perception-action coupling with intent-action coupling and digressed to examples of how tool-use could be described using kinematic data. These kinematic models illustrate the suggestion that the tool-user needs to determine the attractor state of the toolperson-object-environment system and then seek to act such that this state is maintained. Such an approach provides a neat and coherent explanation for the biomechanics of tool-use, without recourse to internal representation of any form (see also Ingvaldsen et al., 1997). However, it begs the question of how does the tool-user know when to stop working, or when should they seek to move from the current attractor state to a different one? If we look again at the stages involved in making a ring (Figure 1), there are, at each stage, a set of perceptual cues to which the skilled tool-user responds, e.g., in terms of the sound of metal as it is struck, the colour of metal as it is heated, the smell of solder and flux as they are heated, the shininess of the metal as it is filed or polished. From the perspective of internal representations, the skilled jeweller would hold a catalogue of these sensory data in memory and draw them out as required to compare with perceptual data as they perform a task. Working with and speaking to jewellers suggests that their interpretation of the state of the metals they work is not as clear-cut as a pattern-matching hypothesis might suggest. Rather, it makes more sense to me that the state of the metals represents another form of affordance; not in terms of the appearance of the metal itself, but in terms of the potential attractor states to which the system might move next. In other words, when the jeweller heats the flux and solder with a blow-torch, it is not simply a matter of waiting until the mix glows with a particular colour (although this can be recognised and, particularly when teaching novices, can be an important signal) but of recognising when the system is moving out of one state and into another. This explanation favours the dynamic nature of the interaction over the static perspective of waiting for perceptual cues. So, why are there differences between the novice and the expert, between good and poor performance? I would argue that the novice or poor performer tends to be over-reliant on perceptual cues, tends to treat the activity as a process of moving from one set of information that requires interpretation to another, tends to treat the manipulation of the tool as a task that is separate from the working of the material. Consequently, their actions possess little, if any, of the smoothness and dynamics of the expert. Conversely, being in the moment and engaging with the materials that they work with means that experts are continually moving between attractor states in the tool-object-environment systems in which they participate. 


\section{Chris Baber}

\section{$\mathrm{NO} \mathrm{T} \mathrm{E}$}

1 The combination of Imperial — inches and thousandths of an inch (thou) - with Metric $(\mathrm{mm})$ was common amongst the jewellers of this generation we spoke to, and suggests an interesting way of conceptualising measurement.

\section{R E F E R E N C E S}

Baber, C. (2003). Cognition and tool use: Forms of engagement in animal and human tool use. Boca Raton, FL: CRC Press.

Baber, C. (2006). Cognitive aspects of tool use. Applied Ergonomics, 37, 3-15.

Baber, C., Cengiz, T. G., \& Parekh, M. (2014). Tool use as distributed cognition: How tools help, hinder and define manual skill. Frontiers in Psychology, 5, Article 116, 1-14.

Baber, C., Cengiz, T. G., Starke, S., \& Parekh, M., (2015a). Objective classification of performance in the use of a piercing saw in jewellery making. Applied Ergonomics, 51, 211-221.

Baber, C., Starke, S., \& Cengiz, T. G. (2015b). Using 1/f scaling to study variability and dexterity in simple tool using tasks. Proceedings of the 59th Annual Meeting of the Human Factors and Ergonomics Society. Santa Monica, CA: HFES.

Bernstein, N. A. (1967). The coordination and regulation of movements. Oxford: Pergamon Press.

Biryukova, E. V., \& Bril, B. (2008). Organization of goaldirected action at a highlevel of motor skill: The case of stone-knapping in India. Motor Control, 12, 181-209.

Bril, B., Rein, R., Nonaka, T., Wenban-Smith, F., \& Dietrich, G. (2010). The role of expertise in tool use: Skill differences in functional action adaptations to task constraints. Journal of Experimental Psychology: Human Perception and Performance, 36, 825-839.

Chao, L. L., \& Martin, A. (2000). Representation of manipulable man-made objects in the dorsal stream. Neuroimage, 12, 478-484.

Chemero, A. (2009). Radical embodied cognitive science. Cambridge, MA: The MIT Press.

Cutler, A. (1994). The hand of the master: craftsmanship, ivory and society in Byzantium. Princeton, NJ: Princeton University Press.

Gibson, J. J. (1979). The ecological approach to visual perception. Boston: Houghton Mifflin.

Grafton, S. T., Fadiga, L., Arbib, M. A., \& Rizzolatti, G. (1997). Premotor cortex activation during observation and naming of familiar tools. Neuoroimage, 6 , $231-236$. 
Guastello, S. J. (2000). Nonlinear dynamics in psychology. Discrete Dynamics in Nature and Society, 6, 11-29.

Higuchi, S., Imamizu, H., \& Kawato, M. (2007). Cerebellar activity evoked by common tool-use execution and imagery tasks: an fMRI study. Cortex, 43, $350-358$.

Ingvaldsen, R. P., \& Whiting, H. T. A. (1997). Modern views on motor skill learning are not 'representative'! Human Movement Science, 16, 705-732.

Johnson-Frey, S. H. (2004). The neural bases of complex tool use in humans. Trends in Cognitive Science, 8, 71-78.

Kamm K., Thelen E., \& Jensen J. L. (1990). A dynamical systems approach to motor development. Physical Therapy, 70, 763-775.

Kello, C. T., Beltz, B. C., Holden, J. G., \& van Orden, G. C. (2007). The emergent coordination of cognitive function. Journal of Experimental Psychology: General, 136, 551-568.

Kelso, J. A. S. (1995). Dynamic patterns: The self-organization of brain and behavior. Cambridge, MA: The MIT Press.

Krist, V. (2012). The cognitive bases of human tool use. Behavioral and Brain Sciences, 35, 203-218.

Latash M. L., Scholz, J. P., \& Schöner, G. (2002). Motor control strategies revealed in the structure of motor variability. Exercise and Sport Sciences Reviews, 30, 26-31.

Martin, A. (2007). The representation of object concepts in the brain. Annual Review of Psychology, 58, 25-45.

Mitra, S., Riley, M. A., \& Turvey, M. T. (1997). Chaos in human rhythmic movement. Journal of Motor Behavior, 29, 195-198.

Newell K. M., \& Corcos, D. M. (1993). Issues in variability and motor control. In K. M. Newell \& D. M. Corcos (Eds.), Variability and motor control (pp. 112). Champagne, IL: Human Kinetics.

Norman, D. A., \& Shallice, T. (1986). Attention to action. New York: Springer.

Parry, R., Dietrich, G., \& Bril, B. (2014). Tool use ability depends on understanding of functional dynamics and not specific joint coordination profiles. Frontiers in Psychology, 5, Article 306, 1-15.

Pye, D. (1968). The nature and art of workmanship. Cambridge: Cambridge University Press.

Rein, R., Bril, B., \& Nonaka, T. (2013). Coordination strategies used in stone knapping. American Journal of Physical Anthropology, 150, 539-550.

Rosenbaum, D. A. (1980). Human movement initiation: Specification of aim, direction, and extent. Journal of Experimental Psychology: General, 109, 444-474.

Roux, V., Bril, B., \& Dietrich, G. (1995). Skills and learning difficulties involved in stone knapping: The case of stone-bead knapping in Khambhat, India. World Archaeology, 27, 63-87. 


\section{Chris Baber}

Schmidt, R. A. (2003). Motor schema theory after 27 years: Reflections and implications for a new theory. Research Quarterly for Exercise and Sport, 74, $366-375$.

Summers, J. J., \& Anson, J. G. (2009). Current status of the motor program: Revisited. Human Movement Science, 28(5), 566-577.

Thelen E. (1990). Motor development: a new synthesis. American Psychologist, 50, 79-95.

Turvey, M. (1990). Coordination. American Psychologist, 45, 938-953.

Van Leeuwen, L., Smitsman, A., \& van Leeuwen, C. (1994). Affordances, perceptual complexity, and the development of tool use. Journal of Experimental Psychology: Human Perception and Performance, 20(1), 174-191.

Van Orden, G. C., Holden, J. G., \& Turvey, M. T. (2003). Self-organization of cognitive performance. Journal of Experimental Psychology: General, 132, $331-350$.

Wagenmakers, E.-J., Farrell, S., \& Ratcliff, R. (2004). Estimation and interpretation of l/f alpha noise in human cognition. Psychonomic Bulletin \& Review, $11,579-615$.

Weisberg, J., van Turennout, M., \& Martin, A. (2007). A neural system for learning about object function. Cerebral Cortex, 17(3), 513-521. 